\title{
HUMOR NAS HQS \\ UMA PROPOSTA DE ESTUDO IDENTITÁRIO VOLTADO À REFLEXÃO DO ENSINO DA LÍNGUA PORTUGUESA.
}

Marcela Marabeli de Moraes é mestranda do Programa de Mestrado Linguagem, Identidade e Subjetividade da UEPG. Bolsista CAPES 2012-2014.

E-mail: ma_marabeli16@hotmail.com

Resumo: Inquieta-nos pensar, neste trabalho, de que modo o humor se faz atuante nas HQ (Ramos, 2009) e em que medida a identidade dos personagens e até mesmo do leitor são aliadas desse recurso. Nosso objetivo é direcionar uma discussão para questões sociais, perpassando a formação de identidade (Hall, 2006). Dessa forma, visamos compreender melhor o olhar crítico do leitor de HQ, dentro e fora da sala de aula (DCE-Paraná, 2008), uma vez que é, entre outros espaços, na escola que se faz presente de forma mais marcada a diversidade social.

\begin{abstract}
Restless us think, this work, how the mood becomes active in HQ (Ramos, 2009) and to what extent the identity of the characters and even the reader of this feature are allied. Our goal is to direct a discussion to social issues, bypassing the formation of identity (Hall, 2006). Thus we aim to better understand the critical eye of the reader $\mathrm{HQ}$, inside and outside the classroom (DCE-Paraná, 2008), since it is, among other places, at school which is present in a more marked social diversity.
\end{abstract}

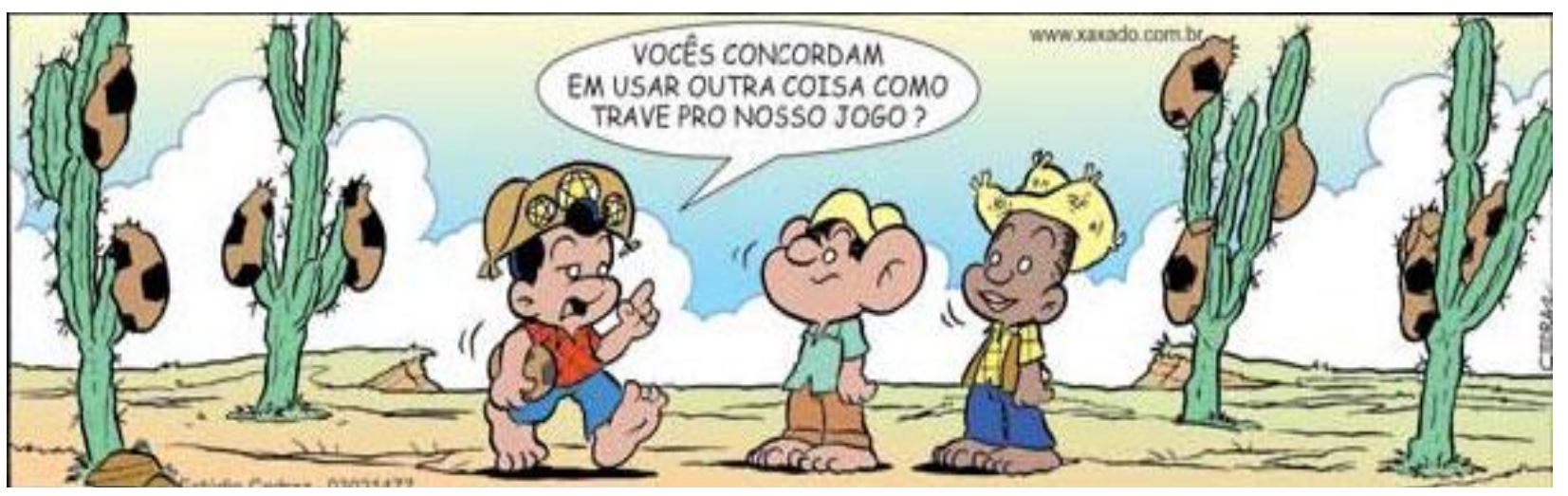

Fig. 1 - Tira cômica da Turma do Xaxado, de Antônio Cedraz

\section{1) Primeiras palavras}

Sabemos que a produção norte-americana Yellow Kid, de Richard Outcault (1895) é considerada a primeira publicação quadrinhística (Pato, 2007, p.44). Para o estudioso supracitado, "os quadrinhos no Brasil surgiram antes disso, ainda no século XIX, pelas mãos do ítalo-brasileiro Ângelo Agostini” (Pato, 2007) com As aventuras de Nhô-Quim, ou Impressões de uma viagem à corte. O autor publicou esse material no dia $30 \mathrm{de}$ janeiro de 1869 na revista Vida Fluminense, tornando o personagem Nhô-Quim representante das HQ no cenário nacional (Scareli, 2003, p.04).

Em princípio, as histórias em quadrinhos eram produzidas no Brasil para o público adulto, mas com o lançamento da revista O Tico-Tico (1905) as produções estenderam para o público infantil, sendo essa o primeiro material de HQ direcionado às crianças. $\mathrm{Na}$ comemoração dos trinta anos da revista O Tico-Tico, o poeta Carlos Drummond de Andrade escreveu para o jornal Correio da Manhã (1955) a crônica Um passarinho (Pato, 2007, p.46), em que articula a história da revista com sua influência sobre o Brasil. 
A popularização das HQ no Brasil também teve como protagonistas Roberto Marinho, proprietário do jornal "O Globo" e das revistas O Malho e Tico-Tico, e Adolfo Aizen, funcionário de Marinho na época - ambos disputavam a hegemonia na indústria dos quadrinhos. Numa viagem aos EUA, em 1933, Aizen constatou a estima das HQ no exterior e no seu retorno apresentou o projeto de editar revistas quadrinhísticas dirigidas ao público infanto-juvenil para Roberto Marinho. Este não aceitou a proposta de sociedade.

O gênero de maior uso pela imprensa eram as charges devido ao seu baixo custo de produção, além disso, o cartunista deveria ser brasileiro pela questão da acessibilidade: o trabalho era executado de acordo com as pautas diária dos jornais. (Pato, 2007, p.49). Durante quase toda a década de 30 a expansão dos quadrinhos no Brasil estava articulada ao desenvolvimento da charge política e dos órgãos de imprensa (Pato, 2007, p. 49). Esse cenário foi modificado a partir de 1937 com a criação do DIP (Departamento de Imprensa e Propaganda) implantado durante o governo Vargas, o que afetou de forma negativa as produções quadrinhística pois muitos materiais eram censurados.

Num salto na história dos quadrinhos no cenário nacional, finaliza-se este estudo histórico com a década de 80 , em que diversos cartunistas contemporâneos iniciaram sua carreira e nesse cenário se destacam: Laerte, Angeli, Glauco e Luis Ge, profissionais estes que atuavam especialmente em publicações jornalísticas como o jornal paulista Folha de São Paulo, tendo como base o humor escrachado e o contexto urbano (Pato, 2007).

Notamos que desde sua gênese até a configuração atual, as HQ sofreram um processo lento e árduo de evolução, caminhando em paralelo com a história mundial e nacional, porém, suas dificuldades e ganhos não se limitaram no social e evoluíram também para as salas de aula. O percurso dos quadrinhos na educação ocorreu de forma tímida com seus exemplares nos materiais didáticos em quantidade restrita. Vergueiro (2007, p.17) lembra que as primeiras revistas de quadrinhos com viés educacional publicadas no estrangeiro, tais como "True Comics, Real Life Comics e Real Fact Comics, editadas durante a década de 1940, traziam antologias de histórias em quadrinhos sobre personagens famosos da história, figuras literárias e eventos históricos".

Em 1944, o Instituto Nacional de Estudos Pedagógicos (INEP) realizou um estudo referente ao conteúdo das HQ tendo como comissão avaliativa professores e orientadores da educação. O trabalho indicou que "os leitores de quadrinhos tornavamse preguiçosos mentais e avessos aos livros” (Gonçalo Júnior, 2004 apud Pato, 2007, p.64), além de incentivar a violência e dominação cultural. Quatro anos após este estudo, Associação Brasileira de Educação (ABE) editou seu próprio código de ética.

Nos dias de hoje, todos os recursos dos quadrinhos estão sendo esmiuçados nas pesquisas acadêmicas ligadas ao ensino para maior compreensão da ferramenta e dos resultados do seu manuseio dentro e fora da sala de aula. Visto como um veículo de comunicação de massa, os quadrinhos podem atingir diversidade de público, uma vez que permitem a abordagem de temáticas que perpassam o contexto social. Além disso, expõem a multiplicidade de opiniões e são uma das formas de proporcionarem vivência à democracia. 
O fenômeno do "achar graça", do humor, instiga diversos pesquisadores em distintas áreas de atuação: psicologia, antropologia, sociologia, linguística, entre outras. Nesse sentido, pode-se compreender que esse instrumento está intrinsecamente articulado à formação de identidade, uma vez que para se produzir e atingir o humor num determinado gênero discursivo, aqui escolhida a tira pela sua maior tendência ao humor imediato e ao discurso crítico, é necessário aplicar os múltiplos conhecimentos sobre as identidades dos envolvidos; ação esta que envolve, direta ou/e indiretamente, todas as abordagens teóricas supracitadas. "Pode-se dizer que o humor é uma esfera na qual circula diversos gêneros", dentre os quais a tira. (Possenti, 2010, p.103).

Sabe-se que o ser humano convive com o humor há milhares de anos e que sua relação com os quadrinhos se faz com propriedade. Dessa forma, Ramos (2009, p.187) afirma que "o humor se confunde com o surgimento das histórias em quadrinhos. Desde o início do século XIX, aumentam os exemplos de desenhos cômicos nos jornais de diferentes países da Europa e das Américas”.

Por conseguinte, o humor ajudou a solidificar a linguagem quadrinhística utilizada nas produções contemporâneas. Em terras brasileiras, "Lailson de Holanda Cavalcanti atribui o primeiro registro de humor gráfico a $O$ Carcundão ${ }^{1}$, publicado entre abril e maio de 1931 em Recife, Pernambuco. O desenho era uma mistura de burro com homem, que pega uma espécie de viga e a quebra em duas partes" (Ramos, 2009, p.187). Nos anos 60, na cidade do Rio de Janeiro, surge o primeiro jornal voltado aos desenhos de humor: a Semana Ilustrada.

Nos anos seguintes, os principais suportes de publicação do humor nos quadrinhos foram os jornais e as revistas. Estas, apesar da pouca tiragem, auxiliaram na influência dos trabalhos dos cartunistas nacionais que sucederam à época; as publicações das revistas reuniam "crônicas, reportagens, sátiras e quadrinhos, todos ligados pelo humor, em geral bastante ácido" (Ramos, 2009, p.190). Diversos nomes tiveram destaque nesse período como: Ziraldo com sua criação Turma do Pererê (1960); Mauricio de Sousa com sua primeira criação, as tiras de Bidu (1959); além de Luis Fernando Verissímo, Jaguar e Henfil.

Na década de 80, segundo Ramos (2009, p. 191), “o humor nacional ganhou novo impulso com a consolidação de uma geração de talentosos autores: Luís Gê, Chico Caruso, Laerte (autor de Piratas do Tietê), Paulo Caruso (Mil e Uma Noite), Angeli (Chiclete com Banana), Fernando Gonsales (Níquel Náusea), Glauco (Geraldão)”. Cartunistas estes que permanecem vivazes nas publicações de diferentes suportes, dos meios digitais aos livros didáticos, os quais formam cidadãos a cada geração.

Ao estudar textos humorísticos se nota sua relação, mesmo que não de forma corriqueira, com diversos tipos de acontecimentos, o que exige a atuação dos conhecimentos diversos do leitor. Possenti (2010, p.27) menciona como exemplo as charges, as quais são tipicamente relativas a fatos "do dia"; e os textos ditos de humor negro, que são produzidos após acontecimentos rápidos, porém trágicos.

Em relação aos textos de humor que independem de acontecimentos atuais para sua interpretação, o teórico remete, por exemplo, às piadas da revista Playboy, as quais

\footnotetext{
${ }^{1}$ Grifo do autor 
se encontram na última página do material e faz menção a qualquer época; "para sua interpretação, invocam uma memória relativa a costumes bastante gerais" (Possenti, 2010, p.28). Nesse sentido, o que se espera do leitor é o conhecimento do jogo de linguagem existente no texto de humor, uma vez que a própria língua é o objeto de humor (Possenti, 2010, p.52).

O comunicar entre textos é um recurso bastante comum no estabelecimento do humor, não só nos quadrinhos, mas em qualquer outro gênero discursivo que trabalhe essa vertente. A abordagem intertextualidade remete não só à interpretação textual como também à noção de humor cultural, ademais exige conhecimentos prévios, partilhados. Possenti (2010, p.146) menciona que "o que nos faz pensar que o humor é cultural, (...) é, mais frequentemente, o desconhecimento dos dados e, talvez, sobretudo, o fato de que, no caso do humor, há uma manifestação clara de seu funcionamento, o riso". Melhor dizendo, quando não há a ação do rir por parte do leitor, se demonstra que não houve o entendimento, marcando a ausência de algum elemento para que o objetivo fosse atingido.

Nesse momento, uma terceira pessoa ou até mesmo o criador e/ou o leitor do texto humorístico, normalmente, explica o conteúdo, o que gera a quebra ou o enfraquecimento de uma das peculiaridades essenciais do humor: a descoberta de seu sentido. "O humor é uma forma de revelar e de flagrar possibilidades de visão do mundo e das realidades culturais que nos cercam" (Travaglia, 1990 apud Schildberg, 2011, p. 01).

Nota-se que o estabelecimento do humor depende de diversos elementos que se conectam para sua eficácia, ou seja, tanto o criador como o leitor e o suporte têm seu papel de atuação, sendo algo que, muitas vezes, vai além da cultura e dos fenômenos textuais. Pode-se entender o discurso humorístico como um dossie $\hat{e}^{2}$ social, em que estão expostos os maiores debates da sociedade junto aos seus valores e deficiência, além do funcionamento da língua, os quais intrinsicamente emergem os princípios do viés identitário dos sujeitos e da comunidade a qual eles pertencem. Dessa forma, torna-se efetivo o desenvolvimento de algumas considerações que nos permita compreender as questões de identidade.

\section{2) Identidade: considerações introdutórias.}

Embora Hall (2006, p.38) discuta que o sujeito relaciona identidade ao fator biológico do ser humano e que vem marcada nos genes com algo natural, a hipótese é desfeita pelo teórico ao afirmar que a "identidade é realmente algo formado, ao longo do tempo, através de processos inconscientes, e não algo inato, existente na consciência no momento do nascimento. Ela permanece sempre incompleta, está sempre 'em processo', 'sendo formada'”. Devido a essa ideia de construção, Hall (2006, p.39) destaca que "em vez de falar da identidade como uma coisa acabada, deveríamos falar de identificação, e vê-la como um processo em andamento"; já Ragagopalan (2003,

\footnotetext{
${ }^{2}$ Grifo nosso.
} 
p.71) fala de "construção de identidades", usando esta terminologia no plural, devido a sua multifaceta e o caráter ilimitado.

Acredita-se, em larga escala, que as identidades estão, todas elas, em permanente estado de transformação, de ebulição. Elas estão sendo constantemente reconstruídas. Em qualquer momento dado, as identidades estão sendo adaptadas e adequadas às novas circunstâncias que vão surgindo. A única forma de definir uma identidade é em oposição a outras identidades em jogo (RAJAGOPALAN, 2003, p.71).

Melhor dizendo, o sujeito se posiciona de distintas formas, de acordo com o contexto dado e faz uso de diferentes identidades conforme os papéis sociais que está exercendo; esta ação é necessária devido às facetas da modernidade, no entanto, pode gerar crise entre as identidades, sendo indispensável uma negociação. Uma vez que a palavra de ordem para identidade é conflito, visão esta discutida no texto, Woodward (2000, p.25) lembra que "as identidades em conflitos estão localizadas no interior de mudanças sociais, políticas e econômicas, mudança para as quais elas contribuem”. Vale ressaltar que não há como refletir sobre crise identitária e não mencionar a atuação da globalização sobre essa questão; entendendo globalização, nesse texto, como "aqueles processos que atravessam fronteiras nacionais, integrando e conectando comunidades e organizações em novas combinações de espaço-tempo, tornando o mundo (...) mais interconectado" (McGrew, 1992 apud Hall, 2006, p.67).

É notório que as diferentes culturas, etnias e línguas aproximaram os povos devido à globalização e a expansão tecnológica, o que gera benefícios e/ou não para o sujeito. Pensando na influência sobre a linguagem, mais especificamente na identidade linguística, Rajagopalan (2003, p.59) diz que "nunca na história da humanidade a identidade linguística das pessoas esteve tão sujeita como nos dias de hoje às influências estrangeiras". Isso se dá devido à invasão da língua inglesa, por exemplo, a qual se faz presente na mídia, na internet, nos aeroportos, enfim, sendo necessário um conhecimento básico da língua para transitar em determinados contextos, e assim se molda o caráter linguístico do sujeito influenciado, ou seja, dos indivíduos globalizados.

No entanto, essa preponderância não ocorre somente na identidade linguística, mas em todas as identidades, afinal, "somos confrontados por uma gama de diferentes identidades (cada qual nos fazendo apelos, ou melhor, fazendo apelos a diferentes partes de nós), dentre as quais parece possível fazer uma escolha" (Hall, 2006, p.75).

Articulando questões identitárias com as de humor, Possenti (2010) apresenta algumas teses sobre piada que podem valer muito bem para as tiras de humor, com a afirmação de que a identidade está sempre representada nessa modalidade de texto humorístico por meio de estereótipos, como, a "loira" é burra, o "gaúcho" é homossexual, o "baiano" é preguiçoso, o "argentino" é arrogante etc. A relação entre identidade e estereótipo se faz na medida em ambos devem ser social, imaginário e construído.

Não obstante, Possenti (2010, p.40) assume que "o fato de que a identidade é uma representação imaginária não significa necessariamente que não tenha amparo real. (...) Por consequência, o estereótipo se caracteriza por uma redução, eventualmente um simulacro". Este entendido pelo mesmo autor como uma "espécie de identidade pelo 
avesso - digamos, uma identidade que um grupo em princípio não assume, mas que lhe é atribuída de um outro lugar, eventualmente, pelo seu Outro". Segue um trecho de Possenti (2010) em que ilustra o simulacro, usando a piada como texto objeto:

Se um grupo se representa tipicamente como "macho" (valente etc.), as piadas dirão dele não só seu oposto, mas seu oposto mais rebaixado possível, considerando certo quadro cultural. Assim, embora o traço "macheza/masculinidade" possa implicar características não ligadas necessariamente ao desempenho sexual (como valentia, ombridade etc), o estereótipo oposto com o qual a piada selecionará o traço "sexualidade". É nesse sentido que se pode dizer que o estereótipo talvez seja um simulacro. (POSSENTI, 2010, p.42).

Outra relação que vale destaque é a da identidade e diferença, uma vez que a primeira se forma por meio da última e sendo uma dependente da outra. Essas abordagens são dados sociais que dependem de escolhas, de tomar decisões. Quando se adota uma posição, se exclui a outra, sendo esta a diferente. Tanto a identidade quanto a diferença estão articuladas ao fator cultural, social e linguístico, sendo o sujeito o agente formador e usuário destas vertentes. Nesse sentido, não há como descartar no refletir sobre identidade as questões diversidade, crenças e a influência da globalização. Para tanto, o presente texto escolheu o gênero discursivo tira, por ser um gênero quadrinhístico que "tente a apresentar um desfecho ligado ao humor" (Ramos, 2009, p.199) e portar o caráter crítico e social, para um estudo analítico.

\section{3) Conhecendo o gênero}

Adota-se nesse estudo o conceito de gênero discursivo bakhtiniano em que estes correspondem a "tipos relativamente estáveis de enunciados" (Bakhtin, 2003, p.262) que organizam o discurso. O presente trabalho optou por uma das tiras da Turma do Xaxado, assinada pelo cartunista Antônio Cedraz, o qual possui publicações em livros didáticos, livros teóricos, além de blogs, revistas e jornais; como objeto de estudo. Para Cedraz (2007), a finalidade de produzir uma "HQ da Turma do Xaxado é mostrar que podemos fazer histórias genuinamente brasileiras. Que temos tipos e gentes que podem ser retratados com dignidade e que podem contribuir na difusão da nossa cultura e cidadania". Silva (2010) ressalta sobre estes quadrinhos que "suas narrativas abordam, com humor e sem subestimar a capacidade das crianças, temas polêmicos da realidade brasileira como, por exemplo, a exploração de homens e mulheres do campo, a pobreza, a corrupção dos políticos, a questão da seca".

O cenário da Turma do Xaxado é uma pequena cidade interiorana, no entanto as aventuras não se restringem somente nesse espaço. Muito da cultura brasileira é exposta nos quadrinhos como: o Saci Pererê, a Mula-sem-cabeça e o Caipora. A turma é constituída por seis personagens principais, os quais possuem características e comportamentos distintos.

A Turma do Xaxado é formada por personagens tipicamente brasileiros, cada um com seu jeito próprio de falar, pensar e agir, passando pelas várias classes econômicas, graus de instituição etc. É uma turminha heterogênea como o povo brasileiro, vivendo 
histórias que falam da nossa terra, encantos e problemas, mas sem perder de vista a universalidade da experiência humana (EDITORA E ESTÚDIO CEDRAZ, 2011).

O personagem principal e que dá nome a turma é o Xaxado, o qual é neto de um famoso cangaceiro que vivia com o bando de Lampião. Sensível, alegre e sempre atento às belezas e aos problemas da vida no campo. Zé Pequeno é o personagem que tem fama de ser um menino preguiçoso, que passa o dia inteiro dormindo. (...) Ele também fica pescando, ouvindo música, namorando, inventando desculpa para não ir à aula. Marieta é a "professora" da turma, vive corrigindo a fala "errada" dos outros. Apaixonada por livros, Marieta adora ler um bom romance, e estudar e aprender coisas novas para, um dia, torna-se professora. Marinês é a namorada de Zé Pequeno e tem o objetivo de estimular a convivência saudável entre o ser humano e a natureza. Arturzinho Albuquerque é o único da turma que tem sobrenome, é egoísta, avarento, vaidoso, chato, exibido, insensível, interesseiro, ademais é filho de um rico fazendeiro da região. Capiba gosta de cantar e tem como inspiração Luiz Gonzaga, o menino também é irmão de Marinês (Editora e Estúdio Cedraz, 2011). Outros personagens ditos secundários são: o Saci, o qual se caracteriza como brincalhão; o jumento Veneta; o porco Linguicinha; o cachorro Rompe-Ferro; a galinha Odete; o galo Valdisnei, os urubus Gervásio e Genésio; os roceiros Tião e Genuíno Gabola; entre outros.

\section{4) Quadro a quadro: uma proposta de análise}
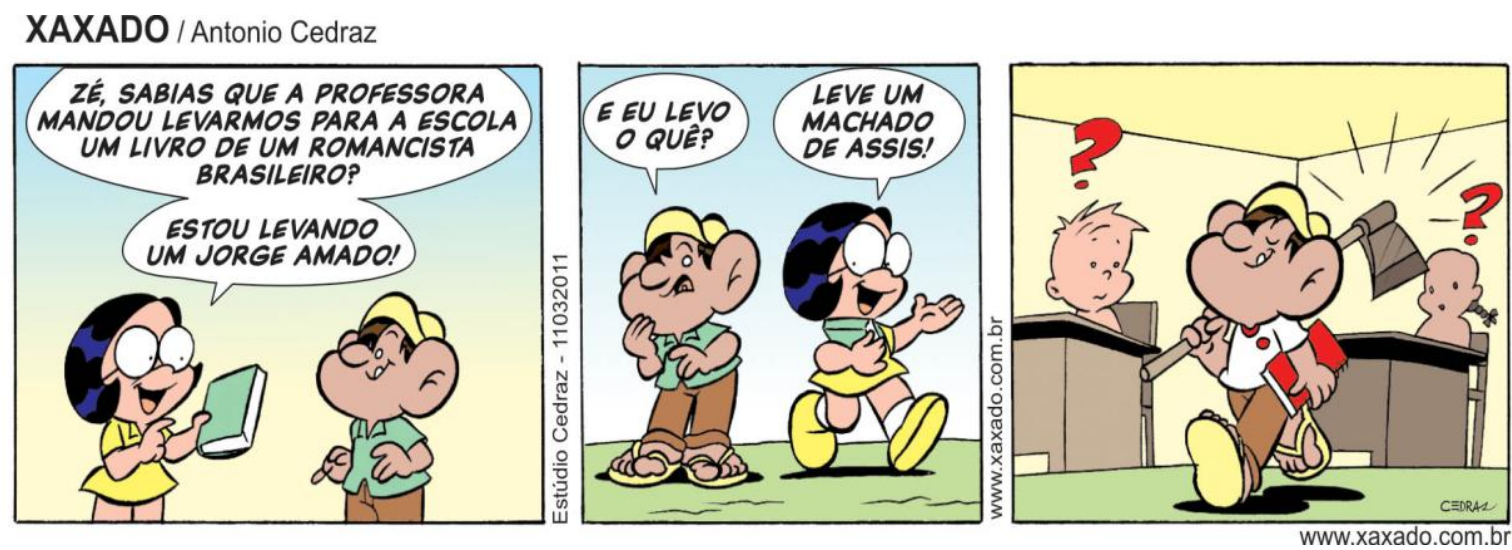

Fig. 2 - Tira cômica da Turma do Xaxado, de Antônio Cedraz. Marieta e Zé pequeno são os personagens

A tirinha em questão do cartunista Antônio Cedraz tem como protagonistas Marieta e Zé Pequeno, personagens estes com interesses e personalidades distintas, até mesmo contraditórias. É notório na leitura e observação da tira o desinteresse de Zé Pequeno pelos estudos e a dedicação de Marieta, a qual lembra o amigo da tarefa solicitada pela professora de Língua Portuguesa, informação esta pressuposta. No primeiro quadrinho a expressão dos dois personagens é similar, aparenta tranquilidade e, até mesmo, alegria pelo encontro; nesse momento o foco mostra que Marieta e Zé Pequeno estão estáticos, para tanto a imagem não mostra os envolvidos de corpo inteiro, privilegiando as mãos (em que está o livro) e a face.

No segundo quadrinho, Marieta permanece com o mesmo semblante, enquanto o de Zé Pequeno muda, apresentando preocupação, nervosismo. Nesta cena, a imagem se 
abre, dando maiores informações ao leitor e o deslocamento de Marieta. No último quadrinho, o cenário se modifica, pois nesse momento, Zé Pequeno está na escola, mais especificamente na sala de aula; essa informação se confirma pela imagem dos alunos sentados em suas carteiras no fundo, além do livro nas mãos de Zé Pequeno, podendo ser um caderno escolar, por exemplo. Aqui a expressão do personagem é de satisfação, orgulho pelo "cumprimento" da tarefa.

Pensando no discurso dos personagens envolvidos nessa tirinha, observa-se a distinção das falas como, por exemplo, a escolha das palavras. Marieta, que tem conhecimentos mais avançados para sua faixa etária e nível escolar, usa formas verbais e saberes literários aliado aos recursos aprimorados o que gera a não compreensão de Zé Pequeno e, por consequência, o humor da tira. Vale ressaltar que uma das características de Marieta é usar as palavras de acordo com a norma padrão e gostar de ler romances, devido a isso em diversas tirinhas da Turma do Xaxado, ela faz referência à leitura e possui um discurso diferenciado dos demais personagens.

No primeiro quadrinho, Marieta diz: "Zé, sabias que a professora mandou levarmos para a escola um livro de um romancista brasileiro?" O uso do verbo "sabias" está na segunda pessoa do singular do pretérito imperfeito do indicativo, como se fosse: (tu) sabias; uma ocorrência pouco usada em algumas regiões do Brasil, para não dizer, nunca usada na oralidade e até mesmo na escrita ordinária, haja vista que os quadrinhos tentam reproduzir o discurso oral, a fala do cotidiano. Na sequência, a personagem usa o verbo "levarmos", o qual está no imperativo infinitivo, como se fosse: para levarmos nós ${ }^{3}$; está ocorrência é comum na escrita, porém, nem tanto na fala do dia a dia, na qual se usaria, dependendo do contexto: "a professora mandou a gente levar para a escola". Nota-se que o contexto ilustrado na tirinha em questão é de informalidade: o encontro de dois amigos no campo, num espaço aberto.

Marieta complementa seu discurso ao contar que escolheu um "Jorge Amado" para a tarefa; ela faz uso de uma figura de linguagem: metonímia, que consiste na substituição de um termo por outro, nesse caso, a troca da obra pelo autor; melhor dizendo, o termo metonímia é definido "como um recurso estilístico que se baseia num processo em que se designa uma realidade ou um conceito por uma outra realidade próxima da primeira: produto/matéria; causa/efeito; abstrato/concreto" (Moreira e Pimenta, s.d apud Cardoso, 2011, p.02). Marieta quis dizer que havia escolhido uma das obras do romancista brasileiro contemporâneo Jorge Amado.

No segundo quadrinho o mesmo recurso é utilizado, a personagem responde o amigo, que não sabe qual obra levar para aula: "leve um Machado de Assis"; dessa forma a troca de termos é novamente realizada e gera o mal-entendido, o qual é apresentado na última cena. Outro recurso utilizado pela personagem é a intertextualidade, ou seja, ela relaciona textos ao citar Jorge Amado e Machado de Assis.

No último quadrinho, Zé Pequeno leva a ferramenta machado para a escola, o que faz ver que o cartunista quer destacar o não-entendimento do personagem em relação à sugestão de Marieta; em contrapartida, a ação de Zé Pequeno não registra que

\footnotetext{
${ }^{3}$ Grifo nosso.
} 
ele não interpretou, pois a partir dos seus conhecimentos empíricos, tudo estava nítido para o personagem, afinal ele poderia ter pensado que Marieta levaria uma pessoa chamada Jorge Amado e não um livro, dessa forma, seria coerente para o personagem levar a ferramenta machado. Destaca-se também o uso da abordagem polissemia ${ }^{4}$, esta "ocorre quando os possíveis sentidos de uma palavra ambígua têm alguma relação entre si" (Cançado, 2008, p.105), ou seja, consiste no emprego de vários significados numa palavra que possui a mesma grafia e fonética, cabendo ao contexto a aplicabilidade apropriada do termo.

Chama atenção também o uso da simbologia na tirinha, a qual reforça a mensagem sugerida pelo cartunista: o ponto de interrogação em cima dos outros alunos, ponto este que representa gramaticalmente pergunta, dúvida; e os riscos sobre o machado segurado por Zé Pequeno, como se iluminasse a ferramenta, direcionando o olhar do leitor e assim reforçasse o "achar graça". Nessa tirinha o humor se faz pela quebra da narrativa, pelo inesperado, até porque o leitor atento tem a noção de que Marieta fala de autores literários e não, no caso de Machado de Assis, da ferramenta.

Sabe-se que há nessa tirinha identidades que dialogam; Zé pequeno e Marieta possuem a mesma idade e estão no mesmo período escolar, no entanto, portam comportamentos e interesses distintos, formando identidades diferentes. Marieta possui uma bagagem de mundo divergente da de Zé pequeno e se pode ver isso durante os discursos. Para tanto, o leitor também precisa de conhecimentos semelhantes aos da Marieta para acompanhar a narrativa com propriedade, sendo a identidade do leitor uma aliada do humor. Não necessariamente o leitor precisa ser admirador das obras de Jorge Amado e Machado de Assis para dominar o texto humorístico em questão, mas se faz relevante ter o conhecimento de que se trata de escritores da literatura brasileira.

Ainda sobre as identidades atuantes na tirinha, nota-se que as marcas identitárias do individuo também se refletem no físico: Marieta é uma personagem que usa óculos e se veste sempre formalmente para sua idade: sapatinhos fechados, meias à mostra e vestido com mangas, combinando com a cor dos sapatos; não que seja uma regra, mas usar óculos, muitas vezes, traz a ideia de intelectualidade, alguém estudioso; diante disso, a identidade de Marieta, naquele momento da tira, não é marcada somente no discurso, mas na vestimenta e no comportamento.

Em relação ao Zé Pequeno há a mesma ocorrência: o uso do chapéu, calça com a barra dobrada e chinelos de borracha nos pés; o que mostra uma identidade típica de um menino do interior que exerce várias atividades no campo, como pescar e subir em árvores, e que não há preocupação com a vestimenta, mas sim com o conforto e a diversão. Zé Pequeno porta a característica do menino simples, e o que prevalece na tirinha é sua identidade de uma criança do campo, do interior. Destaca-se que as identidades de Marieta e Zé Pequeno não representam, necessariamente, identidades fixas dessa faixa etária e sexo, elas estão de acordo com o contexto, com aquele

\footnotetext{
4 “A distinção homonímia/polissemia é de extrema relevância na descrição do léxico de uma língua. Palavras polissêmicas serão listadas como tendo uma mesma entrada lexical, com algumas características diferentes; as palavras homônimas terão duas (ou mais) entradas lexicais. Em muitos casos, a mesma palavra pode ser considerada uma homonímia em relação a determinado sentido e ser polissêmica em relação a outros" (Cançado, p.64, 2008).
} 
momento ilustrado na tirinha; sendo possíveis as mutações, como, por exemplo, Zé Pequeno tornar um menino estudioso com maior interesse na escola.

O leitor a todo o momento da leitura da tirinha em questão também marca suas identidades: leitor de tirinhas, conhecedor literário e do contexto brasileiro e de seu povo. A tirinha selecionada permite inúmeras interpretações, sendo uma delas a hipótese para qual o cartunista visou chamar a atenção para a relevância do estudo e da leitura, uma vez que Zé Pequeno não teria esse comportamento se fosse mais dedicado à escola.

Trazendo esse material para o processo de ensino e aprendizagem de Língua Portuguesa, a qual junto à escola e as outras disciplinas visam a formar cidadãos reflexivos, todas as discussões expostas nesse estudo podem ser realizadas na sala de aula, incluso sobre as identidades atuantes no material e questões de cidadania, o papel do ambiente escolar é ser a ponte entre o aprendiz e sua formação crítica, por meio de diversos gêneros. Para o PCN (1998, p 41) "se o objetivo é formar cidadãos capazes de compreender os diferentes textos com os quais se defrontam, é preciso organizar o trabalho educativo para que experimentem e aprendam isso na escola". As DCE-Paraná (2008, p. 53) aprimoram a ideia ao afirmar que "o trabalho com os gêneros, portanto, deverá levar em conta que a língua é instrumento de poder e que o acesso ao poder, ou sua crítica, é legítimo e é direito para todos os cidadãos”.

Por meio da leitura e do esmiuçar reflexivo de tirinha, a qual faz parte do cotidiano do aprendiz, o professor oferece ao seu grupo de alunos discussões não só teóricas sobre língua, mas culturais e sociais. Nesse processo tanto as identidades do professor quanto as do aluno se reformulam e, dessa forma, há maior contribuição para a formação de um cidadão comprometido com o social. Ademais, nesse trabalho pedagógico muitas identidades serão marcadas e também debatidas, podendo haver empatia com as identidades dos personagens, o que causa maior absorção da mensagem sugerida pelo cartunista e do conhecimento exposto na sala de aula.

\section{5) Considerações finais}

Com este estudo se buscou compreender que é possível aliar humor, identidade e gênero discursivo no refletir sobre a formação humana. No primeiro momento, se projetou um panorama sobre a historicidade do texto humorístico e suas conquistas dentro e fora dos centros acadêmicos, na sequência uma introdução à abordagem identitária, a qual é tão discutida nos dias de hoje; depois a apresentação do gênero discursivo, a tira cômica, e do material escolhido para o estudo analítico, a Turma do Xaxado, de Antônio Cedraz; por fim, a análise da tira, sugerindo a mesma forma de estudo no contexto pedagógico, respeitando as características do grupo de alunos.

Não se teve a intenção de impor nenhuma interpretação definitiva e unificada em relação à tirinha selecionada, o que foi apresentado é mais uma opção de estudo entre diversas que o material possibilita. Também não houve a defesa de que o gênero discurso tira cômica possui a capacidade de suprir todas as necessidades e deficiências do processo de ensino e aprendizagem da Língua Portuguesa, mas a sugestão do uso como mais um instrumento pedagógico e/ou não, por ser este um material de fácil 
acesso, dinâmico, divertido e crítico. O que se defende nesse texto, pensando em sala de aula, é a extrapolação tanto do professor quanto do aluno, do primeiro no nível de diversificar sua aula e ir além das interpretações tradicionais, as quais se estancam no estudo da análise linguística; e o último no nível de aprendizagem e desafio intelectual.

Dessa forma, o estudo não só aprimorou o olhar do leitor para com as tiras cômicas, mas visou compreendê-lo e, assim qualificar os trabalhos seguintes referentes à análise de histórias em quadrinhos, o qual deixou de ser uma leitura somente divertida, para ser reflexiva e, até mesmo, atuante da (re) construção humana. Além disso, o presente trabalho apresentou a necessidade de se abordar os gêneros do discurso, como as histórias em quadrinhos, dentro e fora das salas de aula de língua, num olhar não exclusivamente para a forma, mas para sua funcionalidade.

Sabe-se que devido à necessidade de delimitação das abordagens estudadas, muitos outros assuntos e reflexões que possuem relevância na leitura dos quadrinhos, dentro e/ou fora das salas de aulas, não foram expostos por se vislumbrar um estudo pautado pelo caráter inconcluso. $\mathrm{O}$ trabalho não se esgota nessas páginas, sugerindo novas leituras, reflexões e descobertas.

O pensamento que acompanhou o trabalho é o de que vislumbrar o progresso social e individual é ter consciência de que o começo está na educação.

\section{Referências}

BAKHTIN, Mikhail. Os gêneros do discurso. In: BAKHTIN, Mikhail. Estética da criação verbal. São Paulo: Martins Fontes, 2003. p. 262 - 269.

BRASIL. Secretaria da Educação Fundamental. Parâmetros Curriculares Nacionais: terceiro e quarto ciclos do ensino fundamental: Língua Portuguesa Brasília: MEC/SEF, 1998.

CARDOSO, Liliana Filipa. Metonímia. Disponível em: <http://aquele.do.sapo.pt/fbaul/4006metonimiaXX.pdf>. Acesso em: 22 maio 2011.

EDITORA E ESTÚDIO CEDRAZ. A Turma do Xaxado. Disponível em: <http://www.xaxado.com.br/>. Acesso em: 05 abr. 2011.

HALL, Stuart. A identidade cultural na pós-modernidade. Rio de Janeiro: Dp\&a, 2006.

LEBEAU, Renato. Impulso HQ. Disponível em: <http://impulsohq.com/>. Acesso em: 05 abr. 2011.

PATO, Paulo Roberto Gomes. História em quadrinhos: uma abordagem bakhtiniana. Dissertação (Mestre) - Universidade de Brasília, Brasília, 2007.

PARANÁ. Governo do Estado. Diretrizes Curriculares de Língua Portuguesa para a educação básica em revisão. Curitiba: Base, 2008. 
POSSENTI, Sírio. Humor, língua e discurso. São Paulo: Contexto, 2010.

RAJAGOPALAN, Kanavillil. Por uma linguística crítica: linguagem, identidade e a questão ética. São Paulo: Parábola, 2003.

RAMOS, Paulo. A leitura dos quadrinhos. São Paulo: Contexto, 2009.

RAMOS, Michelle. A vitrine das HQ's nacionais. Disponível em: <http://zinebrasil.wordpress.com/>. Acesso em: 05 abr. 2011.

SCARELI, Giovana. Educação e história em quadrinhos: a natureza na produção de Mauricio de Sousa. Dissertação (Mestre) - Universidade Estadual de Campinas. 2003.

SCHILDBERG, Maria da Conceição Carvalho. As máximas conversacionais e o humor em tirinhas: uma perspectiva pragmática. Disponível em: <http://www.unitau.br/scripts/prppg/enic2008/resumos/MCH0722.pdf >. Acesso em: 22 maio 2011.

SILVA, Marta Regina Paulo. As crianças em... É de menino ou de menina? As relações de gênero nas histórias em quadrinhos infantis. Seminário internacional fazendo gênero - diásporas, diversidades, deslocamentos. Florianópolis. 2010

SILVA, Tomaz Tadeu da; HALL, Stuart; WOODWARD, Kathryn. Identidade e diferença: a perspectiva dos estudos culturais. Petrópolis: Vozes, 2000.

VERGUEIRO, Waldomiro; RAMOS, Paulo. Quadrinhos na educação. São Paulo: Contexto, 2009. 